Thélème. Revista Complutense de Estudios Franceses

ISSN-e: 1989-8193

http://dx.doi.org/10.5209/THEL.54673

\title{
Sade y su idea sobre las novelas: estrategias argumentativas de un polemista discreto
}

\author{
Carola Inés Pivetta ${ }^{1}$
}

Recibido: 12 de diciembre de 2016 / Aceptado: 06 de marzo de 2017

Resumen. En Idée sur les romans, Sade esboza una original teoría sobre el género en cuestión. Nos proponemos detectar los consensos y disensos con otras reflexiones francesas previas sobre esa forma narrativa (en particular las de Diderot y Marmontel), a fin de establecer los puntos de vista novedosos planteados en el ensayo. Para rebatir las teorías que afirman la utilidad moral de la novela, el punto clave en la ofensiva sadiana es el ataque a la idea de naturaleza y de verosimilitud subyacente a ellas. Dado que las discrepancias con esas concepciones hegemónicas durante el siglo XVIII se expresan de modos velados e indirectos, el esclarecimiento de la posición de Sade a propósito de la función de la novela y la relación de los sucesos narrados en ella con la historia y con lo "natural" requiere a su vez el estudio de las estrategias argumentativas utilizadas por este discreto polemista.

Palabras clave: novela; naturaleza; verosimilitud; moral; polémica; Sade.

\section{[fr] Sade et son idée sur les romans : stratégies argumentatives d'un polémiste discret}

Résumé. Dans Idée sur les romans Sade ébauche une originale théorie sur ce genre littéraire. Dans cet article nous nous proposons de déceler les coïncidences et les dissidences avec d'autres réflexions françaises contemporaines sur cette forme narrative (surtout celles de Diderot et Marmontel) afin d'établir les points de vue novateurs formulés dans l'essai. Pour rejeter les théories qui affirment l'utilité morale du roman, le point clé de l'offensive sadienne est l'attaque contre l'idée de nature et l'idée de vraisemblancesous-jacentes à celles-ci. Vu que les divergences avec ces conceptions hégémoniques au cours du XVIII ${ }^{\mathrm{e}}$ siècle s'expriment ici de façons voilées et indirectes, l'élucidation de la position de Sade à propos de la fonction du roman et du lien des faits racontés dans celui-ci avec l'histoire et avec ce qui est "naturel" exige d'étudier également les stratégies argumentatives utilisées par ce discret polémiste.

Mots clés : roman; nature; vraisemblance; morale; polémique; Sade.

\section{[en] Sade's Idea About Novels: Argumentative Strategies of a Discreet Polemicist}

Abstract. In Idée sur les romans Sade outlines an original theory of the novel. This paper identifies his agreements and disagreements with other contemporary French theories on this genre (especially Diderot's and Marmontel's), and in doing so highlights the innovation of Sade's essay. In order to debunk theories that claim the moral authority of the novel, Sade criticizes the idea of nature and of verisimilitude endorsed by them. Since his discrepancies with those eighteenth-century hegemonic conceptions

Universidad de Buenos Aires

carolapivetta@hotmail.com 
are formulated indirectly, Sade's position regarding the function of the novel as well as the connection between the fictional and historical — and the fictional and the "natural"-demands a careful look into Sade's argumentative strategies.

Key words: novel; nature; verisimilitude; moral; polemic; Sade.

Cómo citar: Pivetta, C. I. (2017). "Sade y su idea sobre las novelas: estrategias argumentativas de un polemista discreto". Thélème. Revista Complutense de Estudios Franceses, Vol. 32, Núm. $2: 271-284$.

Las once narraciones que D. A. F. de Sade reúne en Les Crimes de l'amour van precedidas por un ensayo que funciona a modo de prefacio, Idée sur les romans $(I S R)$, que ve la luz en el año VIII del calendario republicano ${ }^{2}$, aunque, tal como las "nouvelles héroïques et tragiques" que encabeza, ha sido concebido por su autor doce años antes en la Bastilla ${ }^{3}$. Con estas consideraciones acerca de una forma narrativa que hacia 1800 ocupa ya un lugar insoslayable en el espectro de los géneros literarios, pero carece aún de un estatuto nítidamente definido, así como de la fuerza consagratoria y el prestigio que cosechará con el correr del siglo XIX, este escritor interviene en las discusiones contemporáneas sobre ese género sin grandes modelos clásicos y por entonces todavía poco codificado en las poéticas, aunque objeto de un interés teórico creciente, debido al auge que vive la novela en la mayor parte de los países europeos sobre todo a partir del siglo XVIII: algunos testimonios de ese inusitado interés en Francia son la Lettre-traité sur l'origine des romans de P.-D. Huet (concebida en 1666, publicada originalmente en 1670 y luego reeditada varias veces por su autor, con ampliaciones, hasta la última en 1711), así como las reflexiones dedicadas al tema que desde mediados del siglo realizan B. d'Arnaud (en el Discours sur le roman publicado junto con su Thérésa, historie italienne en 1745), J.-J. Rousseau (en el prólogo a Julie, ou la nouvelle Helö̈se, de 1761), D. Diderot (en el Éloge de Richardson, de 1761; de aquí en más EdR), F. Marmontel (en Essai sur les romans considérés du côté moral, de 1786) y Mme de Staël (en Essai sur les fictions, de 1795), entre otros ${ }^{4}$. En todos estos escritos, más o menos sistemáticos según el caso, se va delineando un panorama sobre lo que la novela es o debería ser, panorama con respecto al cual Sade se posiciona de un modo original y polémico, si bien esto no siempre resulta evidente de un primer vistazo. Nos proponemos aquí esclarecer su postura con respecto a dicho género y estudiar sus estrategias argumentativas, poniendo a prueba la hipótesis de que su aparente aceptación de ciertos puntos de vista hegemónicos durante el siglo XVIII acerca de la novela no es, en el fondo, sino un modo solapado e indirecto de rebatirlos con mayor efectividad, en circunstancias que lo obligan a eludir la confrontación intelectual abierta.

El prefacio está estructurado en tres partes de peso e importancia desigual: tras proponer al inicio una definición que examinaremos luego, el autor plantea tres aspectos a desarrollar: 1) la etimología del término "novela"; 2) sus orígenes y ejem-

Corresponde al año 1799 del gregoriano.

Esta primera redacción, que data de 1787-88, ha sido editada con el título "Projet d'avertissement" (en Oeuvres complètes du Marquis de Sade, vol. X. Ed. de A. Le Brun y J.-J. Pauvert, [Paris]: Pauvert, 1988), pero no hemos tenido acceso a ella.

4 Enumeramos aquí solo algunos ejemplos relevantes, sin pretensión de exhaustividad; para ejemplos adicionales véase el panorama que traza English Showalter sobre la prosa ficcional francesa del siglo XVIII (2003: 220). 
plos más destacados; 3) las reglas a seguir para alcanzar la perfección en el arte de escribirlas. El primer punto es despachado tras aclarar someramente el vínculo entre novela (en francés, roman) y lingua romana ${ }^{5}$, así como la asociación que más tarde, por derivación, lleva a designar romans a las obras compuestas en aquella lengua que tratan de aventuras amorosas. En cuanto a los otros dos puntos son objeto de un desarrollo más demorado e introducen puntos de vista controvertidos, implícitos o explícitos.

El segundo aspecto abordado da lugar a un examen histórico, un gesto con el que Sade remeda la erudita recapitulación cronológica del mencionado tratado de Huet, quien se remonta hasta la Antigüedad oriental (África septentrional, el Mediterráneo oriental y Medio Oriente) así como griega y romana en pos de rastrear los orígenes de aquella forma. De la genealogía trazada por este crítico del siglo XVII, que con la primera edición de su Lettre-traité, aparecida como prólogo a Zayde de Mme de Lafayette, se propone enaltecer la novela moderna dotándola de una filiación prestigiosa en la epopeya clásica, se retoman en $I s R$ varias ideas, tales como el esplendor alcanzado por la novela entre los griegos, quienes -según Huet- perfeccionan, sometiéndola a las reglas de la épica, la forma bruta e inculta cultivada previamente por otros pueblos orientales, y la visión negativa de la tradición medieval francesa, repudiada por Sade por ser considerada fruto de la imaginación desbordada y la superstición de los bardos galos y por dar un amplio lugar a lo maravilloso. Si en nombre de valores como orden, unidad de acción o proporción entre las partes y el todo -es decir, entre los episodios particulares y la intriga principal-, decoro y verosimilitud, Huet asume la defensa de las novelas de su época ante los numerosos detractores que las acusan de provocar la corrupción de las costumbres, y reivindica su función moral (las llama "précepteurs muets", VII: 127), también aquel escritor perseguido tanto en el Antiguo Régimen como durante el período napoleónico por la inmoralidad e irreligiosidad de su conducta primero y de sus obras luego (aunque buena parte de ellas, como se sabe, haya sido editada anónimamente en vida de su autor $)^{6}$ adscribe, o al menos así lo pretende, a estos criterios clasicistas del académico del círculo de Lafayette. La deferencia de Sade con este se manifiesta no solo en los señalados pareceres comunes en lo que concierne al modo de entender el desarrollo histórico del género novelístico, sino asimismo en la actitud casi reverencial con que cita a su antecesor como una autoridad en la materia, al referirse a él como el "savant Huet" (ibid.: VI). Si bien la definición de las novelas que propone el autor de la Lettre-traité en tanto obras de ficción, compuestas en prosa, que narran aventuras amorosas, cuyo objetivo principal consiste en instruir divirtiendo y que han de mostrar siempre la virtud premiada y el vicio castigado es válida para un subtipo que pronto caerá en el olvido ${ }^{7}$, muchos de los postulados del tratado siguen marcando el

En el imperio romano se designaba así a la lengua vulgar, por oposición al latín escrito y culto (lingua latina).

Por ejemplo Justine, ou les malheurs de la vertu (1791), La philosophie dans le boudoir (1795) y La Nouvelle Justine, suivie de l'Histoire de Juliette, sa sœur (1797).

Showalter considera que "His [Huet's] poetics derived from an already moribund subgenre, the heroic romance" (2003: 213); Camille Esmein (2004), en un análisis menos simplificador del tratado, coincide con este en que la definición inicial y los ejemplos puntuales que proporciona Huet avalan la tesis según la cual se trata de una legitimación de la novela heroica, que tiene su esplendor entre 1640 y 1660 (también caracterizada como barroca, preciosista, histórica o galante), pero detecta un acercamiento, por momentos, a la poética de la novela clásica (o petit roman), subtipo que se impone en Francia después de 1660. Con todo, para hacer justicia a Showalter, hay que decir que también él señala varias contradicciones de la Lettre-traité, atribuyéndolas a "[Huet's] persistent 
tono de las reflexiones sobre esta forma hasta bien entrado el siglo siguiente, a tal punto que es posible reencontrar apreciaciones muy afines en los escritos que d'Arnaud, Diderot y Marmontel dedican a la cuestión. Nos interesa particularmente en lo que sigue elucidar qué sucede en $I S R$ con dos de ellos: la exigencia de verosimilitud de los hechos novelescos y la afirmación de la utilidad moral de la novela.

En cuanto al primero, en un artículo reciente en el que problematiza la cuestión del "realismo" de Sade como narrador, G. Iotti señala hacia mediados del siglo XVIII un cambio que atañe a "la convention classique du vraisemblable":

Au cours de la première moitié du siècle un idéal historique s'impose, qui rejette tout ce qui est imaginaire et irréel, caractéristiques considérées désormais comme puériles et irrationnelles. Mais après 1750 la notion d'histoire intime, c'est-à-dire celle qui est "tournée vers l'évocation du vécu des êtres", va finir par neutraliser l'opposition classique entre histoire et fiction, amenant à une exaltation du genre romanesque (Iotti, 2015: 1-2).

Resulta difícil fijar un momento exacto para la transición, que es sin duda un proceso gradual, de aquel "ideal histórico" a la nueva noción de verosimilitud fundada en la experiencia íntima de un yo. A diferencia de Iotti, J.-M. Goulemot, que también ha descrito este nuevo modo de validación de la ficción novelesca por el cual esta tiende a autentificarse cada vez más en tanto discurso espontáneo de un sujeto privado, retrotrae su comienzo a fines del siglo $\mathrm{XVII}^{8}$. En todo caso, en los ensayos mencionados de Diderot y Sade ya se ha impuesto la tendencia a exaltar la verdad novelesca por sobre la verdad histórica, con lo cual estos escritores de la segunda mitad del siglo XVIII actualizan -adaptándola a la novela- la idea aristotélica de que la poesía es superior a la historia ${ }^{9}$ : al impugnar las novelas que narran una serie de hechos maravillosos o insólitos sucedidos en parajes exóticos, ambos se hacen eco siguiendo en ello a Huet- de la "réaction généralisée contre le romanesque et le merveilleux tels qu'ils apparaissaient dans les romans héroïques et galants de Madeleine de Scudéry ou de La Calprenède" (ibid.: 1). A aquellas obras menospreciadas por su carácter inverosímil y fabuloso, empero, ya no les contraponen un ideal histórico, sino un modelo novelesco alternativo, que pretende ser más realista. Ahora bien, más allá de esta común recusación, lo que Diderot y Sade entienden por realismo difiere considerablemente $y$, por ende, también el tipo de novela que cada uno tiene en mente ${ }^{10}$. Para captar la distancia que separa $E d R$ de $I S R$ comprobaremos a conti-

anxiety about the genre's epistemological status" (ibid.: 212); así explica las oscilaciones del académico, que pasa de una actitud reservada incluso frente a las novelas contemporáneas a su entender más logradas a la firme defensa final del género. El hecho de que el ensayo se haya editado por primera vez junto a la extensa novela histórica Zayde de Mme de Lafayette también expresa esta ambigüedad, ya que, aunque esta escritora suele ser mencionada como exponente del petit roman, justamente esta obra suya es la más barroca y menos clásica de todas las que compuso.

8 "Il est donc nécessaire de penser l'évolution du roman, en cette fin du XVIIe siècle, comme un tout par lequel s'affirme le privée comme essentiel, comme fondement de la vérité de ce qui est conté ou causalité véritable de l'histoire" (Goulemot, 1999: 383); para un análisis pormenorizado de este fenómeno, cf. el final del capítulo aquí citado, que lleva el subtítulo "La nouvelle légitimité de l'écriture" (ibid.: 381-394).

9 En el parágrafo 4 de la Poética Aristóteles afirma que la poesía es más filosófica que la historia pues se ocupa de lo que podría suceder, es decir, de lo universal, mientras que esta última se limita a mostrar en forma objetiva lo realmente ocurrido, lo particular.

10 Iotti proporciona ejemplos tomados de estos autores, así como de B. d'Arnaud. 
nuación cómo en estos ensayos apreciaciones a primera vista coincidentes esconden planteos radicalmente diversos. Tal es el caso del juicio sobre la novela psicológica inglesa. Al ponderar las diversas variantes novelescas de los siglos XVII y XVIII, Sade asigna un lugar privilegiado al subtipo representado por Samuel Richardson y Henry Fielding, de quienes afirma:

C'est Richardson, c'est Fielding qui nous ont appris que l'étude profonde du cœur de l'homme, véritable dédale de la nature, peut seule inspirer le romancier, dont l'ouvrage doit nous faire voir l'homme, non pas seulement ce qu'il est, ou ce qu'il se montre, c'est le devoir de l'historien, mais tel qu'il peut être, tel que doivent le rendre les modifications du vice, et toutes les secousses des passions; il faut donc les connaître toutes, il faut donc les employer toutes, si l'on veut travailler ce genre (1799: XXII-XXIII).

En esta apología de la novela de caracteres inglesa, en palmaria conformidad con el entusiasta elogio que Diderot dedica al autor de Pamela, Clarissa y Sir Grandisson pocos meses después de su muerte, se exalta la nueva posibilidad descubierta por el novelista británico, que consiste en mostrar la interioridad de los protagonistas mediante distintas formas de escritura en primera persona (por ejemplo, el recurso a lo epistolar o al diario íntimo). Hasta aquí, convergen los argumentos de Sade con los motivos por los que Richardson es encomiado en $E d R$ en tanto certero pintor de la naturaleza y de la especie humana por su capacidad para sacar a la luz las motivaciones psicológicas profundas de los personajes y lograr que sus novelas resulten más verdaderas que la historia ${ }^{11}$; pero a continuación se insinúa un leve desvío con respecto al pensamiento del enciclopedista:

là [dans les romans de Richardson et Fielding], nous apprimes [sic] aussi, que ce n'est pas toujours en faisant triompher la vertu qu'on intéresse; qu'il faut y tendre bien certainement autant qu'on le peut, mais que cette règle, ni dans la nature, ni dans Aristote, mais seulement celle à laquelle nous voudrions que tous les hommes s'assujettissent pour notre bonheur, n'est nullement essentielle dans le roman, n'est pas même celle qui doit conduire à l'intérêt; car lorsque la vertu triomphe, les choses étant ce qu'elles doivent être, nos larmes sont taries avant que de couler; mais si après les plus rudes épreuves, nous voyons enfin la vertu terrassée par le vice, indispensablement nos âmes se déchirent, et l'ouvrage nous ayant excessivement émus, ayant, comme disait Diderot, ensanglanté nos cours au revers, doit indubitablement produire l'intérêt qui seul assure des lauriers (ibíd.: XXIII-XXIV) ${ }^{12}$.

La referencia a Diderot es insidiosa, no solo porque las palabras que se le atribuyen no corresponden a ninguna de sus obras, sino porque si la intensidad emocional

11 "Ô Richardson! j'oserai dire que l'histoire la plus vraie est pleine de mensonges, et que ton roman est plein de vérités. L'histoire peint quelques individus; tu peins l'espèce humaine: [...]; l'histoire n'embrasse qu'une portion de la durée, qu'un point de la surface du globe; tu as embrassé tous les lieux et tous les temps. Le cœur humain, qui a été, est et sera toujours le même, est le modèle d'après lequel tu copies. [...] j'oserai dire que souvent l'histoire est un mauvais roman; et que le roman, comme tu l'as fait, est une bonne histoire. Ô peintre de la nature! c'est toi qui ne mens jamais" (Diderot, 1875: 221).

12 El subrayado es de Sade, al igual que en las siguientes citas, a no ser que se especifique lo contrario. 
que deben producir las ficciones para suscitar el interés del lector contemporáneo es efectivamente un aspecto privilegiado por el autor del $E d R$, tal como nota atinadamente Sade, lo que este deliberadamente omite decir es que la conmoción producida por la exposición de las pasiones, muchas veces violentas o excesivas, de los personajes, el pathos que arranca lágrimas y desgarra el alma, solo constituye para Diderot un medio al servicio de una finalidad superior: el objetivo último de tales obras es ejercer una influencia moral duradera en los lectores o, como él mismo lo expresa, inculcar en sus corazones brotes de virtud que puedan germinar cuando sea necesario. Como el escritor de Langres comprueba al comienzo de su opúsculo, así como las máximas de conducta formuladas en términos abstractos y generales no imprimen "aucune image sensible dans notre esprit" (Diderot, 1875: 213), tampoco ese "tissu d'événements chimériques et frivoles" (ibíd.) que en su época suele llamarse novela consigue producir más que una "impression faible et passagère" (ibíd.). A su entender, el mérito de las creaciones de Richardson, para las cuales -opina- habría que acuñar otro nombre, a fin de no confundirlas con aquellas extravagantes novelas que dejan indiferente al que lee, radica justamente en que, al ofrecer un cuadro de las costumbres contemporáneas por medio de la reconstrucción de un milieu cercano al mundo cotidiano de este, permiten su identificación con lo vivido por los personajes. La recreación de este mundo reconocible, verosímil gracias a la acumulación de detalles ("cette multitude de petites choses", ibid.: 218) funciona como condición de posibilidad para que el lector se identifique y por ende se conmueva ante lo leído.

En la capciosa mención que hace Sade del autor del $E d R$ se observa, por lo tanto, una tergiversación de las prioridades establecidas por este: la insistente preocupación por los modos más eficaces de impresionar al lector y sostener su interés ya no está orientada principalmente a que este aprenda a "[se] réconcilier avec les maux de la vie" (ibíd.: 215) ni a que fortalezca "son sentiment de commisération" (ibíd.: 216) llorando empáticamente la suerte de los personajes desgraciados, cuyas experiencias adquieren una validez universal al ser vividas vicariamente por aquel, como quería Diderot, sino que sirve ahora de pretexto para exhibir sin filtros la violencia de las pasiones. Así, la vívida exposición de los sentimientos más secretos de los personajes, la pintura detallada y por momentos patética de las pulsiones humanas (lo que el philosophe denomina "les éclats des passions", ibíd.: 217, y Sade, en un casi imperceptible pero intencionado deslizamiento, designa como "les modifications du vice, et toutes les secousses des passions", 1799: XXIII) se vuelven fines en sí mismos en lugar de vehículo de una enseñanza moral. Además, la constatación de que el interés aumenta siempre que el triunfo de la virtud se ve demorado o impedido, otra idea atribuida arteramente a Diderot ${ }^{13}$, es ilustrada mediante el ejemplo del final de la segunda novela de Richardson, en el que la rica heredera Clarissa Harlowe, drogada y violada por el cazafortunas Lovelace, termina sus días en la soledad y la pobreza, desenlace cuyo atractivo mermaría considerablemente, según Sade, si el libertino hubiera terminado arrepintiéndose de su depravada conducta y casándose con la intachable protagonista; una vez más los silencios del marqués son tan elocuentes como lo que dice: para de-

Asegurando repetir con fidelidad una opinión del enciclopedista, Sade argumenta que de no ser así no se alcanzaría la intensidad emocional necesaria para atrapar al lector; tal atribución es deliberadamente falaz o al menos parcial, pues si bien Diderot afirma en $E d R$ que “[s]i Richardson s'est proposé d'intéresser, c'est pour les malheureux" (ibíd.: 216), también sostiene que "à chaque ligne il fait préférer le sort de la vertu opprimée au sort du vice triomphant" (ibíd.: 215). 
mostrar que las historias en las que la virtud es abatida por el vicio son las más aptas para mantener en vilo al lector menciona Clarissa, or, The History of a Young Lady (1748), pero soslaya deliberadamente la exitosa primera novela del inglés, Pamela, or Virtue Rewarded (1748), cuyo final feliz, anunciado desde el subtítulo, no ha impedido en absoluto que la obra fascinara desde su aparición a lectores de toda Europa. Como puede verse, la adscripción de Sade a las opiniones del autor de La religieuse y Jacques le fataliste -novelas que llamativamente tampoco son mencionadas en el panorama histórico sobre el género trazado en la segunda parte del ensayo- es meramente superficial, pues sus puntos de vista se retoman de manera parcial, cuando no directamente maliciosa o sesgada ${ }^{14}$.

Hay entonces una segunda intención detrás del encomio sadiano del fundador de la novela psicológica inglesa: la de poner en jaque la concepción de la naturaleza implícita en las consideraciones de su primer apologista francés. Con la referencia a la naturaleza que aparece en el fragmento antes citado, introducida a fin de rechazar la tesis de que en las novelas la virtud debe salir necesariamente victoriosa, ${ }^{15} \mathrm{se}$ desliza un cuestionamiento a la representación supuestamente realista de las novelas sentimentales tan populares en el siglo XVIII; a la presunta verdad de una naturaleza concebida en última instancia como moral por Diderot, Sade le contrapone una noción antitética de naturaleza, en su opinión más completa, pues incluye tanto la virtud como el vicio:

c'est donc la nature qu'il faut saisir quand on travaille ce genre [le roman], c'est le cœur de l'homme, le plus singulier de ses ouvrages, et nullement la vertu, parce que la vertu, quelque belle, quelque nécessaire qu'elle soit, n'est pourtant qu'un des modes de ce cœur étonnant, dont la profonde étude est si nécessaire au romancier, et que le roman, miroir fidèle de ce cœur, doit nécessairement en tracer tous les plis (ibid.: XXV).

El sigiloso desmantelamiento de la asociación entre naturaleza y virtud puesto en marcha en la segunda parte de $I S R$ se despliega con mayor contundencia aún en la tercera, en la que el autor enumera algunos principios a seguir para escribir buenas novelas (se trata menos de reglas o prescripciones rígidas que de consejos prácticos dirigidos a aspirantes a novelistas). Al declarar, al comienzo de esta sección, su intención de "répondre à la perpétuelle objection de quelques esprits atrabilaires qui, pour se donner le vernis d'une morale, dont souvent leur cœur est bien loin, ne cessent de vous dire, à quoi servent les romans" (ibíd.: XXX), el hasta allí comedido polemista expresa su ostensible desdén ante la pregunta, tan cara a su época, por la utilidad de las novelas, calificada poco después de "cette ridicule question" (ibíd.)

14 Concordamos en este punto con Chiara Gambacorti (2014: 63), que ha descrito el uso que hace Sade en IsR de las reflexiones diderotianas del EsR como una adaptación y reelaboración pro domo del pensamiento del philosophe.

15 Aristóteles es invocado con el mismo propósito; Gambacorti (2014: 71) ha señalado que también en este caso la recuperación que hace Sade de las ideas del griego es interesada: se trata de una referencia al parágrafo 13 de la Poética, según el cual en la tragedia no es conveniente mostrar a un hombre virtuoso que pasa de la mala a la buena fortuna, pues eso no suscita la identificación del espectador con el héroe trágico, impidiendo por ende que se produzca la catarsis. Sade aplica a la novela estas observaciones originalmente pensadas para la tragedia ática, a fin de justificar, apelando a la autoridad del filósofo, la necesidad de descartar el final feliz para el virtuoso también en esta forma prosaica moderna. 
que preocupa únicamente a sus "froids censeurs" (ibíd.: XXXI). Pero si primero, tomando distancia de quienes preconizan la función edificante del género ${ }^{16}$, desdeña la cuestión de su utilidad, a continuación admite que sirven, en todo caso, para alcanzar un mejor conocimiento del hombre, a quien retratan no como este quiere ser visto, sino como realmente es, una vez que caen las máscaras del orgullo y la ambición. Si bien el argumento se introduce en un principio como una desafiante provocación a esos "espíritus atrabiliarios" cuya mojigatería quedaría al descubierto gracias al poder desenmascarador de este tipo de obra ${ }^{17}$, concebida como "espejo fiel" del corazón humano, enseguida, lejos de dar rienda suelta al debate con estos moralistas despreciados por petulantes e hipócritas, Sade opta por refrenar su ánimo litigioso y subrayar nuevamente la faceta más convencional de su pensamiento: en la medida en que es capaz de captar la interioridad del ser humano despojado de máscaras, la novela -sostiene- se vuelve "le tableau des mours séculaires" de su época ${ }^{18}$. Resuena en esta idea la fascinación diderotiana por "l'étonnante connaissance des lois, des coutumes, des usages, des mœurs, du cœur humain, de la vie; l'inépuisable fonds [sic] de morale, d'expériences, d'observations" (1875: 221) que transmiten las obras de Richardson. Aparentemente nada nuevo bajo el sol en la caracterización sadiana del novelista como un cabal conocedor de las costumbres de su época y "pintor" de la profunda naturaleza psíquica humana; pero el modo en que poco después el marqués se apropia, usando un lenguaje metafórico concienzudamente elegido, de ciertas comparaciones e imágenes comunes hacia 1800 esconde una intencionada transgresión:

le romancier est l'homme de la nature, elle l'a créé pour être son peintre; s'il ne devient pas l'amant de sa mère dès que celle-ci l'a mis au monde, qu'il n'écrive jamais, nous ne le lirons point; mais s'il éprouve cette soif ardente de tout peindre, s'il entr'ouvre avec frémissement le sein de la nature, pour y chercher son art et pour y puiser des modèles, s'il a la fièvre du talent et l'enthousiasme du génie, qu'il suive la main qui le conduit, il a deviné l'homme, il le peindra; maîtrisé par son imagination qu'il y cède, qu'il embellisse ce qu'il voit: le sot cueille une rose et l'effeuille, l'homme de génie la respire et la peint: voilà celui que nous lirons (1799: XXXIII).

En la pluma de este escritor, el vínculo entre la naturaleza y el novelista, al ser postulado como una relación madre/hijo, se estrecha y se vuelve carnal y, más aún, se transforma en una relación incestuosa (cuando el ensayista exige que el artista se vuelva amante de la naturaleza y entreabra su seno). Como ha observado Showalter (2003: 237), en pasajes como este, una comparación habitual e incluso trillada es simultáneamente subvertida y revitalizada.

16 De hecho, Sade formula el problema en modo condicional, evitando afirmarlo como real: "S'il est donc vrai que le roman soit utile, ne craignons point de tracer ici quelques-uns des principes que nous croyons nécessaires à porter ce genre à sa perfection" (1799: XXXI).

17 “À quoi ils [les romans] servent, hommes hypocrites et pervers, car vous seuls faites cette ridicule question, ils servent à vous peindre, et à vous peindre tels que vous êtes, orgueilleux individus qui voulez vous soustraire au pinceau, parce que vous en redoutez les effets" (ibid.: XXX-XXXI).

18 “[L]e roman étant, s'il est possible de s'exprimer ainsi, le tableau des mours séculaires, [sic] est aussi essentiel que l'histoire, au philosophe qui veut connaître l'homme" (ibid.). 
También otros lugares comunes y tópicos usuales en las teorías sobre la novela del siglo XVIII son reelaborados en $I s R$ con una táctica similar, de aparente acatamiento seguido de una subversión que intenta pasar inadvertida. Así, al final del último fragmento transcrito, en el cual Sade justifica las licencias respecto de lo verdadero como prerrogativas del genio, a quien concede el derecho a embellecer la naturaleza con los frutos de su talento, entusiasmo e imaginación, se usan símiles y metáforas asociados al mundo vegetal: el buen novelista, que sabe captar la esencia de una rosa y reproducirla, dándole nueva vida en su "pintura", es contrapuesto a aquel que cuando coge una flor solo atina a deshojarla, a consumirla. Unos años antes, en su Essai sur les romans considérés du côté moral, Marmontel también había avalado las modificaciones de lo real en la ficción con el siguiente argumento:

par la même raison que dans nos jardins nous ne cultivons pas des fruits empoisonnés et des plantes nuisibles, quoique la nature en produise; de même, dans nos fictions, ce n'est pas assez d'imiter, il faut épurer la nature; et singulièrement dans un genre d'écrits qui fait les délices de la jeunesse ce ne doit jamais être au péril de ses mœurs qu'on lui procure des plaisirs (1825: 152).

La comparación con la jardinería sustenta para este teórico y literato la necesidad de purgar los aspectos potencialmente peligrosos, nocivos de la naturaleza, propuesta que Sade impugna sosteniendo que:

la nature[,] plus bisarre [sic] que les moralistes ne nous la peignent, s'échappe à tout instant des digues que la politique de ceux-ci voudrait lui prescrire; uniforme dans ses plans, irrégulière dans ses effets, son sein toujours agité, ressemble au foyer d'un volcan d'où s'élancent tour à tour, ou des pierres précieuses servant au luxe des hommes, ou des globes de feu qui les anéantissent; grande, quand elle peuple la terre d'Antonin et de Titus; affreuse, quand elle y vomit des Andronics ou des Nérons; mais toujours sublime, toujours majestueuse, toujours digne de nos études, de nos pinceaux et de notre respectueuse admiration, parce que ces desseins nous sont inconnus, qu'esclaves de ses caprices ou de ses besoins, ce n'est jamais sur ce qu'ils nous font éprouver que nous devons régler nos sentiments pour elle, mais sur sa grandeur, sur son énergie, quels que puissent être les résultats (ibid.: XXXIX).

La metáfora del volcán desplaza a la del jardín para plasmar una idea radicalmente distinta de naturaleza: aquella visión purgada, edulcorada que defiende expresamente Marmontel es sustituida aquí por la de una naturaleza sublime, esencialmente ajena a cualquier consideración ética, cuyas manifestaciones son comparadas con virulentas e incontrolables erupciones volcánicas, porque posee una desbocada energía, a veces creadora, otras destructiva, pero siempre irreductible a las categorías del bien y el mal.

Como muestra este ejemplo, en $I S R$ los reparos ante las ideas de Marmontel no se expresan abiertamente, igual que los disensos con Diderot se encubren detrás de aparentes coincidencias. Con todo, no cuesta mucho reconocer las insinuaciones con las que aquel experto en el arte del disimulo da a entender la indudable intención polémica que anima su ensayo. Así, poco después, deja entrever otra diferencia con el autor de 
los Contes moraux y Bélisaire ${ }^{19}$ en el siguiente consejo dado a un candidato a novelista: “je n'exige pas de toi, comme les auteurs de l'Encyclopédie, qu'il [le dénouement] soit conforme au désir du lecteur" (ibid.: XXXVIII). A la anterior mención general e indefinida de esos "moralistas", cuya vana pretensión de domesticar las violentas fuerzas naturales y cuya concepción ingenua y falsa de la naturaleza son rebatidas allí con firmeza, sigue esta alusión que, pese al equívoco plural, apunta ya más específicamente a Marmontel, quien firma el artículo "Dénouement" (1765) de la Encyclopédie ${ }^{20}$. Allí este aboga, igual que antes Huet y Diderot, por un final en el que el virtuoso sea premiado y el vicioso castigado, de modo que el lector pueda consolarse ante la visión de la justicia poética consumada al término de la obra. Por el contrario, Sade-que ya en la segunda parte de su ensayo, haciendo una interpretación sesgada de Diderot, se ha declarado partidario de que las novelas exhiban sin reservas los infortunios de la virtud perseguida- rechaza semejante final tranquilizador, supuestamente conforme con el deseo del lector, alegando que no se ajusta a la realidad, a la verdadera naturaleza de las cosas; para ello se basa nuevamente en atribuciones inexactas o al menos imprecisas, ya que en aquella entrada enciclopédica Marmontel nunca se refiere al género novela ni menciona el "deseo del lector" 21.

El análisis pormenorizado de la manera poco escrupulosa e interesada en que Sade retoma ciertos puntos de vista de Diderot y Marmontel -así como antes de Huet y Aristóteles- revela que incluso cuando prevalece una presunta conformidad con las perspectivas dominantes en su época acerca de la función, la evolución histórica, los efectos y las características fundamentales de las novelas, aquel logra infiltrar ideas heterodoxas detrás de esa fachada de aparente respeto a las opiniones mayoritariamente consensuadas. Este reiterado modo de proceder puede ilustrarse mediante un ejemplo más: se trata del pasaje en el que admite la posibilidad de que el novelista se aleje de la verdad histórica, aunque restringiéndola mediante la recomendación de permanecer dentro de los márgenes de lo verosímil:

Mais en te conseillant d'embellir, je te défends de t'écarter de la vraisemblance: le lecteur $[\ldots]$ ne croit plus rien dès qu'il soupçonne qu'on veut le tromper. Contenu d'ailleurs par aucune digue, use, à ton aise, du droit de porter atteinte à toutes les anecdotes de l'histoire, quand la rupture de ce frein devient nécessaire aux plaisirs que tu nous prépares (1799: XXXIV).

Si Sade comienza echando mano a argumentos convencionales con los que parece avalar una representación idealizada de la realidad (el consejo de "embellecer" la realidad, la tácita exigencia de no engañar al lector y respetar los criterios de verosimilitud habituales en la novela de la segunda mitad del siglo XVIII, el contraste entre historia y novela), pronto se aparta de lo previsible y aceptado, cuando hacia el final de la cita se introduce un elemento novedoso: el placer. Mientras que Diderot y Marmontel aprueban la licencia del novelista para corregir los hechos reales

19 El juicio de Sade sobre la obra literaria de Marmontel es ambivalente: elogia la novela mencionada, pero descalifica aquellos "contes à l'eau-rose" (ibid.: XXI-XXII) como "puérilités, uniquement écrites pour les femmes et pour les enfants et qu'on ne croira jamais" (ibíd.) a causa de su carácter remilgado y antinatural, de la afectación y el amaneramiento de los que adolecen.

20 Posteriormente reelaborado e incluido en su obra Éléments de littérature (1787).

21 Trata allí sobre el desenlace de la tragedia y la comedia; el desenlace más perfecto en aquella -afirma- es "celui où succombe le crime et l'innocence triomphe" (Marmontel, 1765: 832). 
solo cuando contribuye a mejorar los gustos y las costumbres del público, el autor de $I S R$ ve con buenos ojos los "atentados" contra la verdad histórica que permiten acrecentar los "placeres" deparados al lector ${ }^{22}$. Por cierto, la aspiración a que las novelas propicien un perfeccionamiento moral es desestimada por Sade, quien, entre los consejos de la tercera parte, incluye el de evitar "l'afféterie de la morale" (ibíd: XXXVII); otras son las reacciones que, según él, sería deseable provocar en el lector, ligadas al goce y el impacto: por eso recomienda al novelista no aburrir al lector repitiendo "ce que tout le monde sait" (ibíd.: XXXV) como hace $\mathrm{R}^{* * *}$-en alusión al prolífico novelista contemporáneo N.-E. Restif de la Bretonne (1734-1806)-, sino intentar deslumbrarlo ${ }^{23}$, y le sugiere evitar todo lo que pueda "nuire aux jouissances que nous [les lecteurs] [...] attendons" (ibid.: XXXIV; itálicas nuestras). Ahora bien, esta reivindicación de lo placentero y lo sorprendente -que en la teoría sadiana desplazan la preeminencia concedida durante la Ilustración a lo útil, acompañado a lo sumo de lo agradable- no implica que el novelista deba limitarse a producir con sus obras un efecto meramente recreativo o impactante; gracias a su mentada capacidad desenmascaradora, las novelas tienen asimismo una utilidad que les es propia: mostrar una verdad que ya no pretende ser de índole moral, sino filosófica.

Antes de concluir, consideremos a la luz de lo dicho la descripción de la novela que aparece al comienzo de IsR como "l'ouvrage fabuleux composé d'après les plus singulières aventures de la vie des hommes" (1799: I): en tal definición, que a primera vista no parece especialmente innovadora, el carácter fabuloso subrayado por el autor acapara la atención, mientras que la singularidad de los hechos que la novela debería narrar, postulada a continuación sin ningún énfasis especial, queda relegada a un segundo plano; pero precisamente tal singularidad, en la que se cifra la poética de lo excesivo y lo bizarro subrepticiamente desarrollada a lo largo del ensayo, constituye el elemento discordante, novedoso de la propuesta de Sade y anuncia su alejamiento de uno de los modelos novelescos más difundido en las literaturas europeas del siglo XVIII -el de la novela sentimental-y su deslizamiento hacia otro en el cual lo singular, lo extraño, lo terrible pasan a ocupar el lugar antes reservado a lo presuntamente representativo y ejemplar. Como ha observado Iotti:

Se fondant sur Aristote et Richardson, sur la nature et la vérité, sur l'efficacité de l'œuvre et l'édification du lecteur, Sade ébauche une théorie du roman qui lui sert à justifier la représentation d'Eros et de Thanatos sous leurs formes les plus terribles $(\ldots)$. En attribuant au romancier le devoir de dire la vérité, il lui fournit un alibi pour s'attarder sur le mal en l'absolvant en même temps de l'accusation d'immoralité (2015: 7).

En efecto, cuando se desbrozan las ideas expuestas por medio de una argumentación usualmente capciosa, en la que hay que desentrañar siempre un sentido inverso

22 Según este último, por cierto, los placeres provocados por la lectura de novelas deben quedar indefectiblemente relegados a la tarea edificante que estas tienen que asumir de manera prioritaria, como afirma en el extracto de $E s R$ citado más arriba ("ce ne doit jamais être au péril de ses mœurs qu'on lui procure des plaisirs", cf. supra), en coincidencia con Diderot, para quien la supremacía de la novela sobre la historia también se funda en la posibilidad de transmitir la virtud no como tesis de una demostración abstracta, sino como impresión concreta que se hace sentir a cada línea (cf. supra).

23 Los desvíos de lo verdadero solo son admisibles, según Sade, "sous la clause expresse d'orner et d'éblouir" (1799: XXXIV-XXXV). 
al aparentemente expresado, la teoría de la novela esbozada por Sade puede leerse como una ratificación de la visión del mundo, formulada insistentemente por los libertinos de sus obras literarias, de acuerdo con la cual lo que la religión y la moral convencional tildan de anómalo, pecaminoso o criminal, es decir, los supuestos desvíos respecto de la norma ético-religiosa, lejos de ser perversiones antinaturales, fenómenos excepcionales o marginales, son conductas normales e incluso frecuentes; se trata, en última instancia, de una justificación de su propia poética, la de la novela libertina y filosófica que él mismo ha cultivado, aunque muchas veces también en su literatura se haya visto obligado a idear modos indirectos para expresar aquella visión del mundo: así, en Justine (1791) o en la tardía La marquise de Gange (1813), la apología del vicio y el crimen, la representación cruda de la violencia de las pasiones y los placeres a los que se entregan voluntaria o involuntariamente sus personajes (ya sean víctimas o verdugos) son disimuladas detrás del discurso pseudomoralizador de un narrador que dice querer instruir al lector, dando lugar a lo que con acierto ha sido caracterizado como una estética de la duplicidad (Gambacorti, 2014: 23 y passim). Si con estas novelas que llevan su firma, al igual que con las obras de contenido abiertamente libertino editadas anónimamente en vida del escritor, este procura desenmascarar la hipocresía del proyecto de una literatura moralizante (ibid.: 96), cuya persistente hegemonía durante el siglo XVIII comienza a resquebrajarse en la transición hacia el XIX, en IsR se propone minar los fundamentos teóricos de dicho proyecto, para lo cual también adopta una estratégica duplicidad, que torna inconducente pretender entender al pie de la letra lo dicho en ese prefacio plagado de deliberadas ambigüedades. Esta ambivalencia, rasgo constitutivo de las obras de Sade que adoptan un registro "decente" (sus nouvelles, dramas, novelas históricas y algunos escritos ensayísticos, por oposición al resto de su producción, abiertamente libertina $)^{24}$, explica por ejemplo la aparente contradicción entre el juicio positivo que le merece a Sade un autor como Richardson, en cuyas principales novelas la prédica moral ocupa, como es sabido, un lugar destacado, y su manifiesta prevención frente a quienes proclaman la utilidad moral de las novelas: si bien dice compartir la admiración generalizada que los hommes de lettres de las generaciones anteriores a la suya, con Diderot a la cabeza, profesan por el autor de Clarissa, conviene tomar con pinzas tal declaración; pues si el philosophe y enciclopedista había quedado fascinado por la novedosa combinación de sentimentalismo (muchas veces rayano en el patetismo), realismo y finalidad edificante ${ }^{25}$ con la cual el londinense funda una nueva variante de la novela moderna, hay en $I s R$ una reevaluación de esos tres componentes y una propuesta tácita de dosificarlos de un modo completamente distinto: Sade descarta sutilmente todo propósito moralizante, cuestiona el pretendido realismo y conserva únicamente el pathos, solo que, al librarlo del yugo de la moral, lo pone al servicio de una finalidad antitética a la que postula Diderot.

El hecho de que en este escrito Sade haya evitado manifestar de manera ostensible las aristas más incisivas de su original pensamiento sobre las novelas y adoptado

\footnotetext{
Seguimos en esto a Gambacorti (2014).

25 La descripción es de Georges May; el entusiasmo de Diderot por Richardson, que consigue hacerlo revisar su condena previa de un género considerado por el philosophe superficial e inapto para cumplir con la elevada finalidad moral de las formas artísticas superiores, es explicada así por May: "c'est, en effet, le moment de sa carrière où Diderot vient de réfléchir sur le théâtre et d'essayer sans trop de succès d'infuser dans ses drames les qualités mêmes qu'il découvre brillament illustrées dans Pamela et Clarissa: réalisme, édification morale, pathétique" (1954: 12).
} 
en cambio un tono conciliador ha sido explicado en función del contexto político-social por diversos críticos, que recuerdan que cuando se edita como prefacio a Les Crimes de l'amour, su autor, blanco de recurrentes y virulentos ataques en la prensa francesa de la época, está afanado en forjarse una sólida reputación de escritor respetable y decente; efectivamente, con el cambio de época que implica el advenimiento del Directorio, Sade ya no tiene que probar su patriotismo revolucionario, sino su seriedad intelectual ${ }^{26}$. En estas circunstancias, resultan comprensibles las ofensivas y los repliegues que caracterizan alternadamente su posición frente a quienes defienden la función moral de la novela, así como el hecho de que astutamente opte por travestir sus controvertidos puntos de vista, que van a contrapelo de las concepciones hegemónicas sobre la novela gestadas al calor del siglo XVIII, parapetándose detrás de postulados ortodoxos y metáforas e imágenes convencionales (aunque muchas veces, como vimos, sutilmente trastocadas). El particular estilo de este polemista encubierto, que obliga a buscar lo novedoso detrás de la fachada del lugar común, a leer entre líneas las diferencias con ciertas ideas prácticamente convertidas en dogmas durante la Ilustración que aquel simula acatar antes de tomar sutilmente distancia de ellas, requiere un lector perspicaz, capaz de vislumbrar los modos velados y alusivos en que se expresan las divergencias con Marmontel y reconocer el trasfondo equívoco que subyace a la admiración, aparentemente sin reparos, hacia Huet, Diderot, Richardson o Fielding. Este lector suspicaz distinguirá, camufladas entre los numerosos clichés que Sade no vacila en explotar insidiosamente (la comparación del novelista con un pintor de la naturaleza, la tópica oposición entre historia y novela, la concepción de esta última como un cuadro de las costumbres de su época, la exigencia de que todo lo narrado sea verosímil y su contracara, la recusación de lo fantasioso, irreal o maravilloso, por mencionar solo algunos de los recapitulados en este trabajo $)^{27}$, muchas ideas que resonarán con fuerza en el siglo siguiente: la reivindicación de lo patológico e impactante, la exaltación de la fuerza de la imaginación y los impulsos o arrebatos creativos del novelista que ya se dejan oír en la teoría sadiana de la novela se tornarán habituales unas décadas más tarde, por cierto, con el Romanticismo francés. Pero todavía en 1800, en el contexto político crecientemente reaccionario y represivo correspondiente a los años del ascenso napoleónico, la ruptura con la idea de que la literatura debe estar ligada a la moral, que preanuncia el Romanticismo por venir e incluso el esteticismo y el decadentismo posteriores, no puede ser asumida sin ambigüedades y desvíos.

\section{Referencias bibliográficas}

Diderot, D., (1875) "Éloge de Richardson, auteur des romans de Paméla, de Clarisse et de Grandisson", in Assézat Tourneux, J. (éd.), Oeuvres complètes de Diderot, tome I. Paris, Garnier Frères, pp. 211-228.

26 Gambacorti (2007), por ejemplo, comenta algunas de las modificaciones realizadas por Sade en las nouvelles compuestas hacia 1787-88 y reunidas en 1799 bajo el título Les crimes de l'amour en versiones ahora más edulcoradas, de las que se eliminan escenas pornográficas y referencias anticlericales; esta crítica observa que allí el marqués procura limpiar su imagen de escritor y hacer olvidar los escándalos suscitados por las novelas libertinas que se le atribuyen, lo cual lo lleva a negar la autoría de Justine al final de IsR.

27 Esto también ha sido señalado por Showalter (2003: 235). 
Esmein, C., (2004) "Le Traité de l'origine des romans de Huet, apologie du roman baroque ou poétique du roman classique?", in Cahiers de l'Association internationale des études francaises [En línea]. $\mathrm{N}^{\circ}$ 56, pp. 417-436, disponible en: http:/www.persee.fr/doc/ caief_0571-5865_2004_num_56_1_1553 [último acceso el 13 de julio de 2016].

Gambacorti, Ch., (2007) “'...ces tableaux du crime triomphant...'. Écriture moralisante et perversion textuelle dans Les Crimes de l'amour du Marquis de Sade", in Dix-huitième siècle [En línea]. № 39, pp. 543-554, disponible en: www.cairn.info/revue-dix-huitiemesiecle-2007-1-page-543.htm; [último acceso el 13 de julio de 2016].

-, (2014) Sade: une esthétique de la duplicité. Autour des romans historiques sadiens. Paris, Garnier.

Goulemot, J.-M. (1999 [1985]) “Les pratiques littéraires ou la publicité du privé”, in Ariès, Ph., Duby, G. \& R. Chartier (éds.), Histoire de la vie privée, vol. III: De la Renaissance aux Lumières. Paris, Seuil, pp. 359-394.

Huet, P.-D., (An VII [1798]) Traité de l'origine des romans. Paris, Desessarts.

Iotti, G., (2015) "Sade conteur 'réaliste", in Revue italienne d'études françaises [En línea]. $\mathrm{N}^{\circ}$ 5, pp. 1-8, disponible en: http://rief.revues.org/1056 [último acceso el 13 de julio de 2016].

May, G., (1954) “Introduction", in Diderot et "La religieuse": Étude historique et littéraire. Paris, Presses universitaires de France, pp. 1-19.

Marmontel, F., (1825) "Essai sur les romans considérés du côté moral", in Bélisaire, suivi de mélanges en prose et en vers [En línea]. Paris, Verdière, pp. 105-176, disponible en: https://books.google.com.ar/books?id=3dQTAAAAYAAJ\&dq=Marmontel,+Essai $+\& h l=$ es\&source $=$ gbs_navlinks_s; [último acceso el 7 de marzo de 2017].

—, (1765), "Dénouement", in Encyclopédie, ou dictionnaire raisonné des sciences, des arts et des métiers, etc., vol. IV., Diderot, D. \& J. d'Alembert (eds.) [En línea]. Paris, Briasson et al., pp. 831-833, disponible en: University of Chicago: ARTFL Encyclopédie Project (Spring 2016 Edition), Morrissey, R. y Roe, G. (eds.), http://encyclopedie.uchicago.edu/ [último acceso el 7 de marzo de 2017].

Sade, D. A. F. de, (An VIII [1799]) Les crimes de l'amour. Nouvelles hérö̈ques et tragiques; précédés d'une Idée sur les romans, et ornés de gravures, vol. I. Paris, Massé.

Showalter, E., (2003 [1 ed.: 1997]) "Prose fiction: France" in Nisbet, H. B. \& C. Rawson (eds.), The Cambridge History of Literary Criticism, vol. IV: The Eighteenth Century. Cambridge y New York, Cambridge University Press, pp. 210-237. 